\title{
Assessment of energy saving and energy efficiency development in Russia and abroad
}

\author{
Tatiana Meshcheryakova ${ }^{1}$,* \\ ${ }^{1}$ Moscow State University of Civil Engineering", 129337, Moscow, Yaroslavskoye shosse, 26, \\ Russia,
}

\begin{abstract}
At the present stage of world economic development, great attention is paid to ensuring sustainable development, including the low energy intensity of industrialized economies. In view of this, the various methods, approaches and mechanisms for energy saving and energy efficiency are of particular importance. One of the most relevant non-state mechanisms is an energy service contract (performance contract). There are preventive mechanisms that have not yet been imposed on market participants, but are capable of qualitatively changing the company's policy regarding the conservation of resources. The goal of the research is to form an understanding of the potential for applying modern energy saving and energy efficiency mechanisms in Russia and the EU. To achieve this goal, the study provides an overview of the current state of the energy service market in these countries, the conditions and directions of its development, identifies key problems in the application of the energy service contract and assesses its potential. A comparative description of the practice of application of the energy service contract and systems of certification of projects and real estate in Russia and the EU is given.
\end{abstract}

\section{Introduction}

Sustainable development of the world economy requires an integrated approach to a variety of issues of ensuring the economic activities of subjects [1]. One of the most pressing issues of our time is the development of territories and cities, which allows the preservation of natural resources, reduction of technological risks, formation of comfortable and waste-free living conditions. In view of this, many practical oriented concepts of energy saving and energy efficiency improvement of economic entities appear. The formation of a unified approach in this aspect to all economic activities is not possible, since there are fundamental differences in the infrastructure, legal, and financial features of the objects.

The modern economy of developed countries is characterized by a high level of energy efficiency. For the Russian economy, the goals have been set to reduce the energy intensity of the gross domestic product of the Russian Federation by no less than 40 percent by 2020 compared with 2007. For these purposes, the decree prescribes:

\footnotetext{
${ }^{*}$ Corresponding author: t.meshcheryakova@mail.ru
} 
- take measures for the technical regulation of economic sectors aimed at improving energy and environmental efficiency;

- prepare a regulatory framework at the level of federal laws providing for economic mechanisms that encourages the use of energy-saving technologies and forms responsibility for non-compliance with available standards;

- provide for budget allocations for implementation of energy saving projects.

Pursuant to the Presidential Decree, the Federal Law \# 261 "On Energy Saving and Improving Energy Efficiency and Amending Certain Legislative Acts of the Russian Federation" was adopted, the purpose of which is to create legal, economic and organizational basis for promoting energy saving and energy efficiency increase. This document contains the basic provisions of energy conservation and energy efficiency, mandatory requirements and possible terms of contracts, especially energy service contract (ESC) concluded for state and municipal needs [2].

In the EU, the issue of energy conservation has been engaged for more than 45 years, and in 2012 a Directive 2012/27/EU was introduced, describing energy efficiency measures to reduce energy consumption by $20 \%$ by 2020 . When introducing the practice of ESC implementation in Russia, the benchmark is accumulated experience in this matter of the EU countries, since this form of contract originated in France, although it was most prevalent in the United States and China, but in the EU, ESC are also actively used.

The practice of modern technological development has shown that the lowering in the energy intensity of products is based on the introduction of modern technologies and energy management standards. Improvement of the energy efficiency is not only a technical problem required technological solutions, but also a managerial problem involving organizational measures. In view of this, the modern problem of the approach to the effective management of the organization's energy resources - the energy management system (EMS), based on European standards, is of great importance.

Of great importance is the issue of energy efficiency and environmental friendliness in individual industries. The construction industry is one of the most capital-intensive ones. At each stage of the reproduction process (including: industrial production of building materials, design of real estate, construction of objects, operation of real estate), the issue of efficient use of energy resources and focus on the sustainability of the environment takes a special place. Ecological and energy efficient approaches to design and construction are laid down in "green" standards.

The aim of the study is to identify the features of the application of key mechanisms for energy saving and energy efficiency and to determine their development trends.

The object of the study are organizations engaged in energy-intensive activities.

The subject of the research is the process of implementing measures for energy saving and increasing the energy efficiency of the Russian economy and the economies of the EU countries.

To achieve this goal, the following tasks were formulated and solved during the study: - analysis of significant mechanisms of energy saving and energy efficiency improvement in Russia and EU countries;

- identification of the barriers in the development of effective mechanisms for energy saving and energy efficiency in Russia and EU countries;

- to mark the direction of further development of mechanisms for energy saving and energy efficiency in Russia and EU countries. 


\section{Materials and Methods}

ESC is a generally recognized mechanism for implementing energy-saving measures and improving the energy efficiency of Customer's facilities in all economically developed countries.

At the moment, the development of ESC in industrial enterprises, where there is the greatest potential for energy saving and energy efficiency, should be of particular interest for the national economics. Unfortunately, the practice of optimizing energy-intensive production processes and providing the infrastructure of existing industrial enterprises based on ESC, despite the obvious advantages of this mechanism, has not yet developed in Russia.

Customers planning to use an ESC mechanism should take into account that compensation for energy service company (ESCO) costs is possible according to different schemes for dividing revenues from saving energy costs:

1. Shared Savings - division of income derived from energy savings. The use of this type of ESC is based on an accurate calculation of savings income, which is carried out by the methods which are easy to understand and verify. The share of savings income for each ESC participant is determined in advance. The income of the ESCO includes the repayment of the loan and the agreed payment of all services rendered. This income is divided by the term of the ESC. All financial mutual benefits are negotiated in advance, therefore, all possible risks associated with the failure to achieve planned performance are undertaken by the ESCO. According to international experience, the share of the customer (enterprise) in the income from savings is about $20 \%$;

2. First-Out / First Pay-Out. When using this type of contract, the ESCO receives fully $100 \%$ of the savings during the payback period of the ESC. Unlike the previous method of revenue sharing, which pre-determined income from savings for the main ESC participants, in this type of contract only expenses for energy-saving measures are pre-calculated and specified.

Often there is a combination of 2 presented methods: revenue sharing and quick payback;

3. Guaranteed Savings / Chauffage. When using this type of ESC, the enterprise is guaranteed to reduce energy costs. In addition to the implementation of the project of energy saving, the ESCO checks the energy management of the enterprise. During the term of the contract, ESCO undertakes to pay energy bills. The company pays a fixed amount to the ESCO, averaging $85-90 \%$ of the base payments. The actual amount of savings received does not directly affect the Customer's payments.

The principles of distribution of income received from saving energy costs of the Customer are well-known for the professional community, however, in most cases customers do not have a complete picture of the options and flexibility of the distribution of savings.

At the conclusion of an ESC between the Customer and the ESCO according to the requirements established by the Government of the Russian Federation, the ESCO is fully responsible for fulfillment of the terms of the contract and assumes all financial risks associated with the failure to achieve the planned savings, committing to pay a penalty for each day of delay in the fulfillment of its obligations [2].

From the point of view of management organization, the company has an appropriate energy management mechanism. The practice of modern technological development has shown that the reduction in the energy intensity of products is based on the introduction of modern technologies and energy management standards. The improvement of energy efficiency is not only a technical problem requiring technological solutions, but also a management problem. To solve this management problem, the international standard ISO 
50001: 2011 has been developed. Energy management systems - Requirements with guidance for use [1,3]. A significant effect of the implementation of the ISO 50001: 2011 standard is financial savings by reducing energy consumption. The potential for reducing energy consumption in the EU is $25-28 \%$ by 2020 compared to the baseline $[4,5]$. In the $\mathrm{EU}$, it is planned that as a result of measures to reduce energy consumption, the growth in demand for energy resources will be "frozen" and greenhouse gas emissions will be reduced by almost 1 billion tons of $\mathrm{CO}_{2}$ by $2020[4,5,6]$.

The ISO 50001 standard is intended to create an EMS, as well as to certify such systems. On the basis of the standard, there are tools for assessing, analyzing and verifying the results of management activities in the field of energy consumption. The ISO 50001: 2011 standard largely coincides with the European standard EN 16001: 2009 adopted in most European countries. ISO 50001 compared to EN 16001 contains additional requirements that relate to the following aspects: the appointment of a management representative for energy management, the identification of the organization's energy characteristics, the existence of an organization's plan for managing energy resources, and the procedures for purchasing equipment and energy resources. ISO 50001: 2011 replaced EN 16001: 2009, as well as the North American standard ANSI MSE 2000: 2008.

The structure of the requirements of ISO 50001: 2011 is similar to the structure of requirements of ISO 14001: 2004, and also ISO 18001: 2007. Thus, it becomes possible to create an integrated management system, since the general procedures for conducting internal audits, management review, corrective and preventive actions, document and record management, etc. are available.

The essence of the implementation and maintenance of these standards requirements is that, based on their own capabilities, needs and goals, the organization itself determines specific action plans and procedures. The requirements of the standards are formulated as prescribing what should be done, but not defining a specific action plan. The standard is based on the Deming's methodology PDCA (Plan-Do-Check-Act), which describes the cycle of continuous improvement. At the planning stage, the standard assumes the identification of: - the main characteristics of the energy consumption of the enterprise; baseline (energy consumption in the absence of systemic effects aimed at energy efficiency and energy saving); - the main indicators characterizing energy efficiency, legislative and other requirements; - target indicators.

The main idea of implementing ISO 50001: 2011 is that it is not a program of measures being implemented, but a management system with mechanisms for monitoring, analyzing, and correction actions.

Key elements of the standard are:

- Energy policy that developed by the top management of the organization;

- Goals and objectives in the field of energy management;

- Plans for the implementation of goals and objectives;

- Providing resources and authority to the management representative and group of employees of the organization; responsible for the implementation of energy management;

- Periodic energy analysis of the organization;

- Establishment of basic lines of energy consumption;

- Establishment of energy efficiency indicators, which are designed for a specific organization and, in conjunction with the baseline, allow you to assess changes in energy consumption;

- Operational control and procedures in terms of significant energy consumption;

- Measurements and documentation in part of energy management;

- Periodic management review of the EMS.

In addition to the investment mechanisms for energy saving and mechanisms for organizing energy management, there is an energy saving mechanism based on the concept 
of ecological and energy efficient construction and operation - "green" construction standards. Green building is the philosophy in which the environmental impact is minimal, and the quality of life and habitat meets the highest requirements. Minimizing the impact on the environment and providing high quality habitats are achieved by new approaches to the design and use of green technologies. The design covers not only the stages of construction and operation, but also the full life cycle of buildings: from concepts of development, use of environmentally friendly and renewable building materials to its demolition and recycling of materials. Microclimate quality, habitat quality, including transport accessibility, proximity to the aquatic environment and visual comfort and infrastructure are assessed. The green building minimizes the consumption of energy and water resources, uses nontraditional renewable energy sources and secondary energy resources, and reduces the amount of waste.

In different countries of the world, green building requirements are formulated in rating systems for the stability of biosphere. The most well-known and used both abroad and on the territory of Russia are the following European "green" standards presented in the order corresponding to the prevalence level: BREEAM - environmental assessment method (United Kingdom); DGNB - Certificate of Sustainable Construction (Germany); HQE - the concept of high quality environment (France). One of the most well-known and applied "green" standards, in addition to European systems, is the US rating "The Leadership in Energy \& Environmental Design" - LEED [7,8].

National standards in Russia are just prepared and are not yet widely distributed. In Russia, a standard has been adopted - GOST R 54964-2012 "Conformity assessment. Environmental requirements for real estate".

All standards listed are voluntary certification systems. In European countries, there is a significant practice of applying green standards, with an already established market. In Russia, the certification market is in its infancy (mainly certifying office buildings), but it has a great potential for use, especially for commercial real estate.

\section{Results}

It should be noted that the practice of implementing energy saving measures in the EU countries is exemplary, and all Russian effective tools and mechanisms for energy saving and energy efficiency are based on European prototypes.

At the moment, there is no uniform methodology for relating industrial enterprises to a group with a certain degree of energy intensity (the category "high energy intensity" is very conditional). The leaders of most Russian industrial enterprises are skeptical and traditionally implement energy-saving measures not comprehensively, but on a case-bycase basis, provided that they have the necessary amount of their own funds and confidence in the low level or absence of risks. Of course, there are examples of enterprises on the market with an established energy management system, modern tools and mechanisms for optimizing the structure of energy costs. However, this is rather an exception, unlike in European countries, where much attention is paid to energy optimization processes. In the industrial sphere at the federal level, the policy of energy conservation and energy efficiency is declarative in nature and there are largely no prerequisites for reducing energy intensity. This issue was particularly acute with the abolition of mandatory energy testing, which abolished the procedure for the audit of energy facilities for enterprises with large energy costs of core activities. Logically, we can assume that the energy service, which has not yet received proper distribution now, will find a place in the Russian economy. However, on April 19, 2018, the Order of the Government of the Russian Federation \# 703$\mathrm{p}$ approved a comprehensive plan of measures to improve the energy efficiency of the economy of the Russian Federation. The comprehensive plan provides for the 
implementation of measures to improve the energy efficiency of the economics of the Russian Federation, including industrial enterprises, and it is also planned to activate the ESC mechanism.

For multi-apartment buildings (MAB), the rules for determining the energy intensity class of a property entered into force in 2016 , according to which you can see the intended trajectory in the field of energy saving and energy efficiency of facilities. The introduced regulatory document will provide a border in identifying energy-intensive real estate, which implies the following: if the energy survey revealed that the MAB corresponds to a low energy efficiency class (below class D), it is prescribed to implement energy-saving measures recommended in the Energy Passport Annex. One of the implementation mechanisms can be an ESC.

The implementation of ESC for objects of various purposes in countries with almost half a century of experience in using ESCs involves the use of the most efficient modern technologies, the quantitative composition of which is sometimes of 30 positions. At the same time, ESCO strives to achieve large savings, not always using measurement and verification techniques, which is also typical for our country (national standard GOST R 56743-2015). One of the most popular methods of measurement and verification of energy saving in international practice is based on the American standard "The International Performance Measurement and Verification Protocol» (IPMVP), which became widespread in the form of a whole complex of national and regional standards, as well as protocols on measurement and verification for individual states of America. Despite the absence of a generally accepted unified system of methods for assessing the energy efficiency of energysaving measures, the focus on maximizing the effect of their implementation and the longterm effect determines the use of only high-quality equipment and proven technologies.

Everything is different with regard to the practice of applying ESC in Russia - in the pursuit of savings and the short payback period of the project, companies sometimes resort to such innovative technologies for which there is no significant application practice and this is certainly fraught with high risks not only for ESCO, but also for the customer. In case if the planned effect is not achieved in a short time, the technologies used are changed to other with methods of selection, which entails temporary losses during the implementation of ESC and additional ESCO costs, which means a reduction in the project payback period.

It should be noted that the low level of interest of business leaders and owners living in the MAB has many reasons. For industrialists who have a conscious need to implement energy-saving measures using the ESC mechanism, this is explained by the negative experience in the implementation of ESC, due to the weak regulation of the energy service market. In view of their own lack of qualification, customers encounter unscrupulous companies that mislead them, implementing one-time measures, using equipment that does not provide a long-term effect, and there is a substitution of concepts that fit into the norms of the law. Energy service contract is defined as a form of contract for the provision of energy conservation services. In the Federal Law \# 261, it is written: "energy service agreement (contract) - an agreement (contract), the subject of which is the implementation by the contractor of actions aimed at energy saving and increasing the energy efficiency of the use of energy resources by the customer". At the same time, the essence of the mechanism oriented to the implementation of the project at the expense of the ESCO, which compensates for all costs based on savings of funds for the Customer's energy resources, is not given anywhere. For another category of customers - owners living in the MAB, the lack of interest in the use of ESCs is due to the lack of information on the possibility of applying this investment mechanism.

The financial model of energy saving in the EU countries differs in the fact that between the owners of the facility and ESC share the savings, regardless of the amount of savings 
over a period of time. Such contracts are usually concluded for a longer period than in Russia. The owner does not pay for the project, but receives a percentage of the savings during the contract period and all the savings at the end. EU countries are also characterized by a high percentage of participation in financing projects with the help of loans from commercial banks, or with the help of state and municipal bond issues. Non-energy-saving expenses are covered, as a rule, by building owners or at the expense of budget subsidies. The payback period for ESC is from 5 to 15 years; however, municipal contracts are usually concluded for a longer period, and short-term contracts of up to three years prevail in the industrial sector. It is important to note that in some EU countries (for example, in Germany), the impetus for applying ESC is strict and stringent state requirements, active support at the federal level, assistance in procurement, and interest of financial institutions to invest in energy service.

In addition to the investment mechanism, we will evaluate the market of the organizational mechanism that complies with the ISO-50001 standard [9-11]. According to international statistics, Germany ranks first in terms of certification. Russia, according to the results of 2017, came in 11th place (Fig. 1).

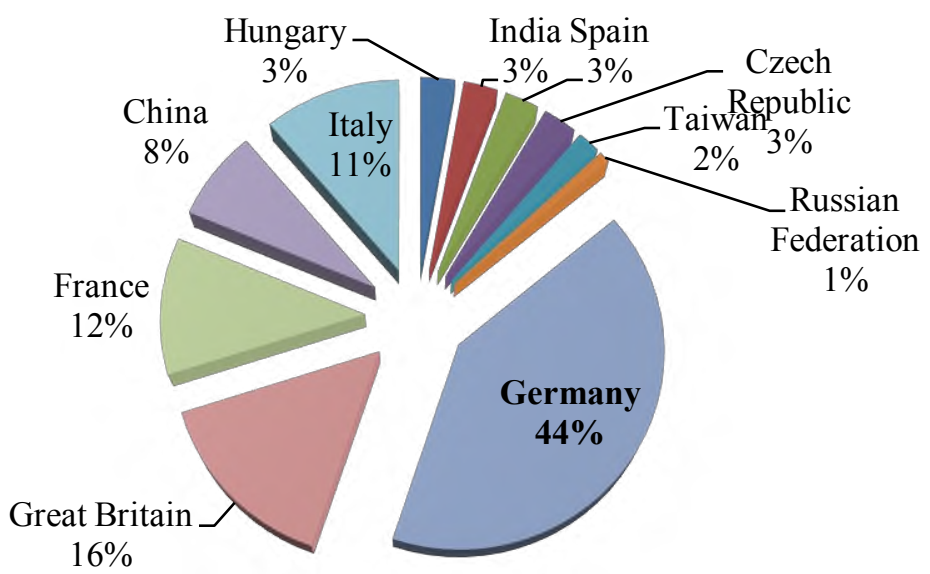

Fig. 1. ISO-50001 certification market (Top 11 countries)

Let us summarize the results of the research, according to the mechanism that determines the technical issue of creating an environmentally friendly and energy efficient building that meets modern requirements for a sustainable environment. In 2017, the green construction market in Russia was formed as a niche market and entered development at the plateau stage (Fig. 2).

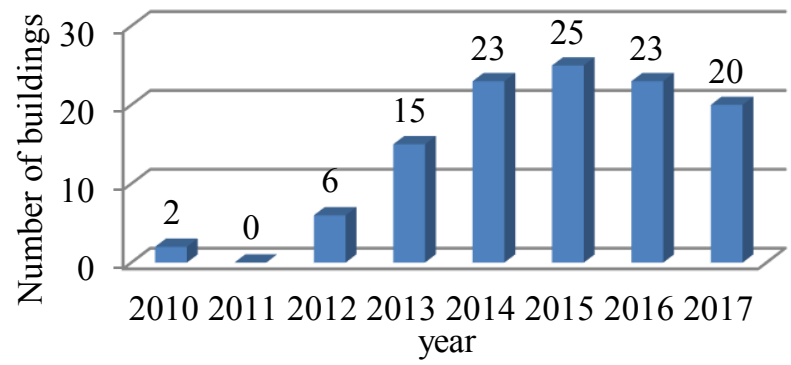

Fig. 2. Dynamics of "green" certification of buildings in Russia 
The results of certification for 2018 have not been formed, but there is an understanding of high performance, the type of the FIFA championship and the certification of sports buildings and structures where the championship was held. For these purposes, the national standard RUSO was created in the summer of 2018. Thus, in addition to office buildings, sports facilities have appeared in Russia that are certified to "green" international and national standards. However, such an increase in certification of such objects will not continue in the near future, since it was due to a one-time need.

\section{Discussion}

Let us note the trends in the development of the considered mechanisms for the implementation of energy-saving measures. There are different points of view between the many experts adhere when assessing the potential for energy saving and applied mechanisms. In Russia, according to government programs and strategies, the growth of the energy services market is predicted. However, there are questions that led to many contradictions. First of all, it should be noted that from this year on, mandatory energy revisions were canceled, which formed a significant share of the energy service market. Now an energy revision is conducted only on a voluntary basis. Certainly, there will be supporters of the democratization of these procedures, however, it is possible to reasonably cite a number of premises that testify not to the benefit of the changes being made.

If you consider any international or national standards in the energy or related field, for example, "green" standards: a free form of certification, implying a focus on the continuous improvement of all business processes of an organization under the guidance of experienced, success-motivated managers, implies their personal interest in certification. The interim result is the unstable market of customers, characterized by a low level of interest in the certification of construction projects and finished real estate. Initially, the free form of certificate market circulation allows identifying problems, shortcomings and outline changes, with the possibility of using mandatory forms of certification for individual market participants. As a continuation of the development of the certification issue, the requirements of international organizations (for example, FIFA imposes requirements on sporting buildings and facilities where competitions are held), as well as any stakeholders, mainly foreign investors, on "habitat". That is, on the basis of the practice of voluntary certification, new conditions arise for the formation of the principles of mandatory certification. Thus, the requirements of regulatory documents do not keep pace with the market, voluntary certification systems or standards appear, and then these requirements become mandatory and enter into new mandatory standards.

Taking into account the analysis of this example, it is possible to reveal the diametrically opposite direction of the development of the energy service market. Initially, tough conditions were created for potential Customers of energy services, massively obliging the majority of industrial enterprises to conduct energy audits, and at a certain moment, limiting this circle to subjects with annual needs exceeding 10 thousand of conditional tons. Currently, the state is shifting off-budget development tasks financing mechanisms for energy saving measures to the level of issues of self-organization of an enterprise, in view of which there are doubts about state interest in the development of an ESC mechanism for the industrial sector of the economy. At the same time, it is precisely by lobbying ESCO interests in industry, where there is a need for expensive energy-saving measures, which cannot be financed by the budget of not only the Customer, it is possible to achieve a tremendous cumulative effect that can reduce the energy intensity of the Russian economics [12]. 


\section{Conclusion}

The above mechanisms for energy saving and energy efficiency increase have different specific target audiences and varying degrees of distribution in Russia and EU countries. According to the results of the analysis, it is possible to identify key aspects that determine the advantages of each mechanism:

1) ESC, as an investment mechanism, has the following advantages:

- Absence of the need for capital investments of the Customer, in view of the fact that the burden of expenses falls on the ESCO;

The priority of the principle of financial non-engagement of the Customer provides new opportunities for the implementation of many complex capital-intensive projects of energy saving and energy efficiency at the facilities of the Customer. In this issue in Russia, there are still two fundamentally non-obvious formulas for the application of the theme: - the system of financing ESC; - distribution of financial risks. The problems of forming an accessible toolkit for long-term financing of projects using ESC remain unsolved. Russian banks are afraid to take risks in financing ESC for a variety of obvious reasons. One of the intended directions in addressing this issue is the transition from traditional corporate financing to asset-based financing.

- Low production and financial risks for the Customer.

2) The EMS, as an organizational mechanism, is possible to be applied by various organizations, regardless of their scale and type of activity. It can be implemented in the organization both separately and with other management systems, such as ISO 9001, ISO 14001, ISO 45001 and others. As a result of the use of the EMS, it is possible to reduce energy consumption at enterprises by at least $1.0-1.5 \%$. This completely pays for the expenses of the enterprise associated with the creation of elements of the EMS.

The implementation of the EMS provides the following benefits for the organization:

- improving the energy performance of the production cycle;

- timeliness of effective energy saving measures;

- receiving return from these actions in the form of financial profit;

- increase its energy efficiency and competitiveness in the market;

- implementation of plans to improve the efficiency of energy saving by analyzing the current energy consumption relative to the expected;

- introduction and application in the daily activities of organizations of various legislative, regulatory, contractual and other requirements and obligations.

- performing important regulatory functions in climate change;

- improving the reliability of work and capitalization of the organization;

- reducing the energy intensity of products or services.

3) "Green" standards, as a technological mechanism (environmental and energyefficient construction) for the organization that certifies its projects and finished objects, provides the following benefits:

- high competitiveness in the promotion of its project, consistent with the principles of sustainable environmental development;

- a guarantee that the construction of the facility used technology that meets the basic principles of sustainable development of territories;

- intensifying the search for innovative solutions that minimize the impact on the environment;

- reducing operating costs and improving the quality of the working and living environment;

- compliance of the object with the standard, which demonstrates progress towards corporate and organizational environmental goals, which gives it the right to be publicly called the Green Real Estate Company. In other words, certification according to Green 
Standards and achieving high energy efficiency indicators is becoming a significant competitive advantage, which increases the profitability of the project by increasing the rent and reducing costs, which is highly valued by potential investors.

All the presented mechanisms are of great importance in energy saving and increasing the energy efficiency of economies both in Russia and in the EU countries. In Russia, all mechanisms are developing. In some issues, for example, in energy service without reaching the peak of development, stagnation is already predicted. However, in the EU countries, despite the development of the certification market for organizations, real estate and project documentation, there are many problems that require a systematic approach to the solution. In many EU countries, as well as in Russia, energy service in industrial sectors is developing poorly, having one of the largest energy saving potentials. This question should be paid attention to when developing and updating existing national and international programs that contain the economic and organizational aspects of energy saving and energy efficiency.

\section{Reference}

1. L. Georgeson, M. Maslin, M. Poessinouw, Geo: Geography and Environment, 4(1), e00036 (2017) doi: 10.1002/geo2.36

2. E. Ganebnykh, A. Mottaeva, T. Larinina, E. Petrova, MATEC Web of Conferences, 170, 01044 (2018) doi.org/10.1051/matecconf/201817001044

3. K. Locmelis, D. Blumberga, U. Bariss, Energy Procedia, 147, 202-206 (2018) doi.org/10.1016/j.buildenv.2018.02.012

4. P. Bertoldi, F. Diluiso, L. Castellazzi, N. Labanca, T. Serrenho, Energy Consumption and Energy Efficiency Trends in the EU-28 2000-2015 (Publications Office of the European Union, Italy, 2018) doi:10.2760/6684

5. I. Potekhin, V. Mischenko, A. Mottaeva, A. Zheltenkov, E3S Web of Conferences, 33, 03020 (2018) doi: 10.1051/e3sconf/20183303020

6. EEA, Trends and drivers in greenhouse gas emissions in the EU in 2016 (European Environment Agency, Copenhagen, 2018) doi:10.2800/691394

7. D. Zhikun, F. Ze, V.W.Y. Tam, B. Yu, L. Shenghan, I.M.C.S. Illankoon, M. Sungkon, Building and Environment, 133, 32-40 (2018) doi.org/10.1016/j.buildenv.2018.02.012

8. A. Bowen, K. Kuralbayeva, E.L.Tipoec, Energy Economics, 72, 263-275 (2018) https://doi.org/10.1016/j.eneco.2018.03.015

9. W.A. Pelser, J.C. Vosloo, M.J. Mathews, Journal of Cleaner Production, 198, 642-653 (2018) doi.org/10.1016/j.jclepro.2018.07.071

10. G. Ridauraa, S. Llorens-Cerveraa, C. Carrilloc, I. Buj-Corral, C. Riba-Romevaa, Resources, Conservation and Recycling, 131, 75-85 (2018) doi.org/10.1016/j.resconrec.2017.10.030

11. M. Dieterle, Ph. Schäfer, T. Viere, Procedia CIRP, 69, 764-768 (2018) doi.org/10.1016/j.procir.2017.11.058

12. T. Meshcheryakova, MATEC Web of Conferences, 106, 06021 (2017) doi: 10.1051/matecconf/201710606021 